The Consumption Consequences of Couples Pooling Finances

\author{
EMILY N. GARBINSKY
}

JOE J. GLADSTONE*

*Emily N. Garbinsky is an Assistant Professor of Marketing at the University of Notre Dame, Mendoza College of Business, Notre Dame, IN 46556 (egarbins@ @d.edu). Joe J. Gladstone is an Assistant Professor of Consumer Behaviour at University College London, School of Management, UK (j.gladstone@ucl.ac.uk). Both authors contributed equally; order was determined randomly. The authors would like to thank Jonathan Berman, Tim Gilbride, AnneKathrin Klesse, Sandra Matz, Abigail Sussman, and Joe Urbany for their feedback on earlier drafts, as well as Rachel Becker, Frankie Brockman, Lori Tinkey, and Rongel Chance Yee for their research assistance. In addition, the authors are grateful for the helpful comments from participants at the 2016 APS conference in Chicago, the 2016 CFPB conference in Washington, D.C., the 2017 CFP Academic Research Colloquium in Arlington, the 2017 SCP conference in San Francisco, the 2017 Summer Conference on Consumer Financial Decision Making in Boulder, the 2017 Marketing Strategy Meets Wall Street Pre-conference in San Francisco, the 2017 ACR conference in San Diego, and the 2018 Yale Customer Insights Conference in New Haven. 


\begin{abstract}
When couples decide to share their lives, they must also decide how to pool their finances. In this paper, we ask: Does the type of bank account from which one spends (joint vs. separate) affect the type of products one chooses to buy (utilitarian vs. hedonic)? Real-world evidence from analyzing bank transaction records (study 5), as well as data collected from experiments in the field (studies 1 and 2) and lab (studies 3 and 4), converge to support the hypothesis that couple members who spend from a joint bank account are more likely to choose utilitarian (vs. hedonic) products, than those who spend from a separate bank account. We find that these different spending patterns are driven by an increased need to justify spending to one's partner that is experienced when money is pooled together. If a hedonic product becomes easier to justify (study 4), the effect of account type on spending patterns disappears. These findings have important theoretical and practical implications for better understanding financial decisionmaking within romantic couples.
\end{abstract}

Keywords: Consumer Spending, Romantic Relationships, Hedonic Consumption, Need for Justification, Interpersonal Decision-Making 


\section{The Consumption Consequences of Couples Pooling Finances}

Consumer decisions do not take place in a vacuum; they are shaped by their social environment and made within the context of close interpersonal relationships, including romantic relationships. While past research has acknowledged that romantic partners influence consumption, the conditions under which this takes place, and the mechanisms through which this occurs, are surprisingly understudied in the marketing literature (Cavanaugh, 2016; Gorlin \& Dhar, 2012; Simpson, Griskevicius, \& Rothman, 2012). From the literature that is available, it is clear that couple members think about their partner when making decisions for joint consumption (Lerouge \& Warlop, 2006; Scheibehenne, Todd, \& Mata, 2011). However, even when making a purchase for individual consumption, couple members must still consider the feelings and judgments of their partner when deciding what to spend their money on (Simpson et al., 2012).

In this paper, we argue that the type of account from which an individual spends has an important, yet previously unacknowledged, influence on the degree to which couple members consider their partner when making a purchase. Specifically, we hypothesize and show that couple members are more likely to consider whether their partner will judge their purchase when spending from a joint (vs. a separate) bank account, because they feel a greater need to justify their purchase decision to their partner. Importantly, we suggest that this increased need for justification will make individuals more likely to choose utilitarian products (which are easier to justify), rather than hedonic products, compared to couple members who spend from a separate account. In line with this underlying mechanism, we demonstrate that in situations where hedonic products become easier to justify, the effect of account type on spending patterns disappears. 
This research makes several contributions. Theoretically, we hope to further our understanding of consumer behavior in relationship contexts, a topic that is surprisingly understudied in the marketing literature (Cavanaugh, 2016; Gorlin \& Dhar, 2012; Simpson et al., 2012). In addition, we hope to contribute to an emerging stream of research on financial decision-making in couples. Most of the classic work in this area has focused on decisions made jointly by both members of the couple (Burns, 1977; Burns \& Granbois, 1977; Davis, 1970, 1971, 1976; Munsinger, Weber, \& Hansen, 1975). Although large or important purchase decisions are still frequently discussed and made by both couple members together, scarcity of time has led to an increasing delegation of purchase decisions to just one of the partners (Lerouge \& Warlop, 2006). Therefore, the majority of daily spending decisions, such as what to buy at the grocery store or at the mall, are made by one couple member alone (Belch $\&$ Willis, 2002; Cunningham \& Green, 1974). For this reason, we chose to focus our investigation on individual, rather than dyadic, decision-making processes in relationships. Lastly, it is estimated that $82 \%$ of couples in the United States maintain at least one joint bank account with their partner (Todorova, 2007). Given the wide proliferation of joint accounts, better understanding how (and why) spending from this type of account can influence certain product choices is a practically relevant area of investigation.

\section{Antecedents of Joint versus Separate Accounts}

It is first important to acknowledge and understand the process by which couples decide whether to pool their finances, or keep them separate. Past research has found that most couples do not consciously decide how to organize their money (Pahl, 1995). Instead, money management practices are often based upon ease or convenience (Vogler, Brockmann, \& Wiggins, 2006), and typically reflect the dominant institutional arrangements in a couple's home 
country (Cheal, 1993; Zelizer, 1989). Although ease or convenience is frequently cited as a primary motivation concerning the decision of whether or not to pool finances, we acknowledge that there may be other motivations at play.

In an effort to better understand various antecedents, we surveyed 413 married participants, asking them how they pool finances with their spouse, and to explain, in an opentext format, what motivated this decision. These responses were then coded into one of five categories based on previous literature and our own hypotheses: 1) ease / convenience (Vogler et al., 2006) , 2) better budgeting / improved finances (Treas, 1993), 3) pre-existing beliefs about how money should be managed in a relationship based on cultural norms (Cheal, 1993), 4) conflict reduction (Dolan \& Dolan, 1993), and 5) justification / need for accountability (our proposed mediator). We also included a sixth category ("Other") for responses that could not cleanly be classified into one of these five pre-determined categories (for descriptive statistics, see the Methodological Details Appendix; MDA 1).

Consistent with past work, ease or convenience was the most common reason provided, with 143 participants $(34.6 \%)$ offering sentiments such as "That's just how we have done things since we have been together. It works." Of note, married individuals with all joint, or all separate accounts, did not differ in the extent to which ease or convenience was mentioned as a primary motivation for account choice, $\chi^{2}=0.0, p=.99$. Although this was the most frequently cited reason, joint and separate account holders did differ in the extent to which other motivations were referenced. For example, individuals who pooled their finances together were more likely to indicate that this decision was based upon a pre-existing belief about how money should be managed in marriage, $\chi^{2}=30.96, p=<.001$, whereas individuals who kept their finances completely separate were more likely to report that this decision was based upon a belief that 
doing so reduces arguments over money, $\chi^{2}=10.79, p=.001$, and results in better budgeting and more optimal financial decisions, $\chi^{2}=10.85, p=.001$.

Although couples often have different motivations for deciding whether to pool their finances, or keep them separate, it is worth noting that only one participant reported that justification, or the need to improve accountability, was their primary motivation. This suggests that the need for justification (our proposed mediator) does not appear to be an antecedent of account choice, with couples not primarily driven to pool their finances based on the need to justify spending within the relationship. Consistent with past research, our data instead illustrate that the majority of couples who pool their finances do so as a result of convenience $(n=86$, $38.9 \%)$, or a normative belief that this is what married couples should do $(\mathrm{n}=82,37.1 \%)$. We thus argue that the perceived need to justify spending to one's partner is a consequence of the decision to use joint bank accounts, which can influence consumers' purchase decisions.

\section{The Psychological Consequences of Joint versus Separate Accounts}

To the best of our knowledge, the psychological effects of maintaining joint versus separate bank accounts have not received prior empirical attention in the field. However, previous literature has demonstrated how the source of money can influence how it is both perceived and used. Specifically, the theory of mental accounting describes how consumers organize their finances by mentally ascribing money for different purposes (Heath \& Soll, 1996; Thaler, 1999). In contrast with basic economic principles, this research suggests that people do not treat money as fungible (Kahneman \& Tversky, 1984; Thaler, 1985). Instead, they mentally segregate their money based on its function, which in turn influences their financial decisions. For this reason, setting money aside for a particular purchase reduces the likelihood of spending that money on something else (Heath \& Soll, 1996; Soman \& Lam, 2002). The process of mental 
accounting has been used to explain a wide range of financial decisions, including savings (Shefrin \& Thaler, 1992), borrowing and debt (Prelec \& Loewenstein, 1998; Sussman \& O’Brien, 2016), and effects of payment on consumption over time (Gourville \& Soman, 1998).

In line with past research on mental accounting demonstrating that money set aside for different purposes affects how consumers think and feel about it, we similarly suggest that money set aside in different accounts (separate vs. joint) affects the degree to which couple members feel they need to consider their partner when making purchase decisions. Although spending from either type of account reduces the total amount of money available for the couple to utilize in the future, we hypothesize and show that the very nature of joint bank accounts (being to denote shared rather than separate money), causes those spending from a joint (vs. a separate) account to feel a greater need to justify purchase decisions to their partner.

Secondary data supports this hypothesis. If those spending from a joint account feel a greater need to justify their purchases, as we propose, we would expect them to also report consulting their partners more frequently on their spending decisions. Using the British Household Panel Survey, a nationally representative survey following 12,000 people over 20 years (Brice, Buck, \& Prentice-Lane, 2002), we find that even after controlling for a range of demographic characteristics, those with joint accounts are significantly more likely to report asking permission from, or informing their partner about their purchases, compared to individual account holders (for details, see MDA 2). This finding underscores the possibility that those spending from a joint account experience an increased need to justify purchase decisions, compared to those spending from a separate account.

\section{Consequences for Consumption}


If those spending from a joint (vs. a separate) account feel the need to choose products that are easier to justify, an important question arises: What products are easy to justify? An overwhelming body of evidence suggests that it is far easier for people to justify purchasing utilitarian products than hedonic ones. There are several reasons why this is the case. Hedonic consumption is often associated with guilt, and it is difficult for consumers to justify choices which will make them feel guilty (Kivetz \& Simonson, 2002; O'Curry \& Strahilevitz, 2001; Strahilevitz \& Myers, 1998). Additionally, one of the main benefits of hedonic goods is experiential enjoyment, which is hard to justify (Sela, Berger, \& Liu, 2009). Furthermore, it is often easier to construct reasons for purchasing utilitarian products, and the more reasons one can generate, the easier it is to justify that purchase (Hsee, 1995; Shafir, Simonson, \& Tversky, 1993). Given the evidence that utilitarian products are easier to justify than hedonic ones, and given our hypothesis that those spending from a joint (vs. a separate) account experience a greater need to justify their purchases, it follows that those spending from a joint account should be more likely to choose utilitarian, rather than hedonic, products.

But will couple members who spend from a joint account always prefer utilitarian products over hedonic ones? Given the many situational factors that could affect the ease with which hedonic purchases can be justified, we believe this is not the case. If those spending from a joint account are more likely to purchase utilitarian products due to an increased need for justification, as we predict, this preference should no longer be observed in situations where hedonic products are easy to justify. Existing literature has suggested that one way consumers justify hedonic choices is by using the presence of a discount as justification (Cavanaugh, 2014). For example, when purchasing vice (hedonic) foods, consumers prefer a price discount (to a bonus pack) because it acts as a guilt-mitigating mechanism, allowing them to more easily justify 
the purchase (Mishra \& Mishra, 2011). Thus, when those spending from a joint account can more easily justify hedonic consumption, they should be more likely to purchase hedonic products. More formally, we predict:

H1: Couple members who spend from a joint (vs. a separate) account will be more likely to choose utilitarian (vs. hedonic) products.

H2: The effect of spending from a joint (vs. a separate) account on product purchase patterns will be mediated by the need to justify spending to one's partner.

H3: Those spending from a joint account will be more likely to choose hedonic products when they are sold at a discount (vs. regular price), because discounted products are easier to justify.

\section{Overview of the Current Research}

We conducted five studies across multiple settings to test our hypotheses. Studies 1 and 2 provide support for hypothesis 1 . In study 1 , we conducted a field experiment by randomly endowing participants with separate or shared money and observing how this affected actual product choice. In study 2, we provide additional causal evidence through another field experiment, where couple members were randomly assigned to make a real purchase using their own money, from either a separate or joint bank account. In study 3, we tested hypothesis 2 by showing that the need to justify spending to one's partner, rather than the need to justify spending to oneself, mediates the effect of joint (vs. separate) accounts on utilitarian product purchase. In study 4, we provided support for hypotheses 3, by demonstrating the role of a price discount. More specifically, we show that when participants are presented with an opportunity to buy a hedonic product that is easy to justify, in this case because the item is discounted in price, those spending from a joint account become more likely to choose the hedonic product. In 
addition to providing support for our hypotheses, we also address an important confound:

hedonic products tend to be purchased for a single couple member, whereas utilitarian products tend to be purchased for both couple members. We eliminate this confound in all lab and field experiments (studies 1-4) by keeping the product category constant.

Our central goals in this research are to identify and describe a novel effect of spending from joint (vs. separate) bank accounts on consumption patterns, demonstrate the psychological mechanism underlying this effect, and provide an important instance in which this pattern is attenuated. As far as we know, our research is the first to experimentally test the consumption consequences of pooling accounts. Given the challenge in replicating the complex interdependent processes involved in account pooling in lab and field experiments, we have supplemented our findings with observational evidence from real bank account data. In study 5 , we utilized over 160,000 transaction records to examine the cumulative effect of real purchase decisions made by couple members with joint or separate bank accounts. Consistent with hypothesis 1 , we show that there is a real-world correlation between holding a joint (vs. a separate) account and spending more money on utilitarian (vs. hedonic) products. Although we believe that testing for evidence across various domains - including experiments, surveys, and real-world behavior - is a major strength of this research, our work does have limitations, which we acknowledge in the General Discussion.

\section{Study 1: Calendar Study}

The aim of study 1 was to provide initial support for hypothesis 1 by randomly assigning participants to spend using either separate or joint funds. To this end, study 1 used a single-factor between-subjects design where the type of funds participants received was manipulated (separate vs. joint). The dependent variable was the participants' choice between a hedonic and utilitarian 
product. We predicted that individuals spending with joint (vs. separate) money would be more likely to choose the utilitarian product over the hedonic one (hypothesis 1).

\section{Product Pretest}

The purpose of this pretest was to ensure that one of the products presented to participants was indeed perceived as hedonic, while the other product was perceived as utilitarian. Seventy-one students $\left(51 \%\right.$ male, $\left.M_{\text {age }}=19.41\right)$ enrolled in an introductory marketing course completed this pretest as a favor to the instructor. They saw a picture of two calendars: a football calendar that contained a picture of the university's football team on the cover as well as the subsequent pages for each month (the hedonic product), and a university calendar that contained a picture of the university's iconic buildings on the cover as well as the subsequent pages for each month (the utilitarian product). To ensure that the products were equally attractive, both calendars were the same size, listed the same university-relevant events for each month, and prominently displayed the name of the university on the cover.

All participants read the definition of hedonic and utilitarian products: "Hedonic products are pleasant and fun; they are enjoyable and appeal to your senses. Utilitarian products are useful, practical, or functional; they help you achieve a goal. It is possible for a product to be equally hedonic and utilitarian. It is also possible for a product to be higher on one quality than it is on the other." They then rated how hedonic and utilitarian the calendars were (from $1=$ not at all, to $7=$ very much). In addition, they indicated how much they liked the two calendars (on a scale from 0-100).

As expected, paired-samples t-tests revealed that participants perceived the football calendar $(M=5.72, S D=1.37)$ to be significantly more hedonic than the university calendar $(M$ $=3.77, S D=1.72), t(70)=7.43, p<.001$, and the university calendar $(M=5.25, S D=1.32)$ to 
be significantly more utilitarian than the football calendar $(M=3.66, S D=1.66), t(70)=-7.29, p$ $<.001$. There was no significant difference in the degree to which participants reported liking the football calendar $(M=73.21, S D=20.25)$ or the university calendar $(M=71.21, S D=23.05)$, $t(70)=.52, p=.61$, suggesting that one product was not strongly preferred over the other.

\section{Participants and Procedure}

The study was run at a private university in the mid-west United States the Friday before a home football game. The university is well-known for its football team, and dozens of alumni events are offered on campus the Friday before a home game. One of the study authors and two research assistants set up a table in the entrance to the basketball arena, an area of high pedestrian traffic where university merchandise is sold. A sign was used to attract and recruit participants in committed romantic relationships to take part in the study. More specifically, the sign read: "In a committed romantic relationship? Contribute to the university's research efforts by taking a fun 5 minute survey."

After approaching the table, one of the research assistants asked participants if they were in a committed relationship. If not, they were told they were ineligible for the study and given a small candy. Otherwise, they were handed a one-page response sheet to complete, and told that they needed to complete it to receive one of the snacks on the table. Over the course of 8 hours, 68 participants $\left(57 \%\right.$ male, $\left.M_{\text {age }}=47.28\right)$ completed the study.

The response sheet was used to randomly assign participants to either the separate or joint condition. Those in the joint condition were given a bag that contained $\$ 1$ worth of nickels, and after receiving the bag, they read: "This money is for both you and your partner. Please write both your name and your partner's name on a sticker (located on the table) and place the sticker on the bag." Those in the separate condition were also given a bag that contained $\$ 1$ worth of 
nickels, and then read: "This money is just for you (and not your partner). Please write your name on a sticker (located on the table) and place the sticker on the bag."

After placing the sticker on their bag of nickels, all participants read that they would be using this money to buy one of the products on the table (the football calendar or the university calendar). All participants were given an opportunity to examine both calendars before making their decision. We also measured gender, age, relationship length, and whether one's partner was present at the time of the decision. Lastly, all participants completed a manipulation check, indicating the extent to which they perceived the money in the bag as theirs alone versus shared between them and their partner $(1=$ totally my money, $5=$ totally shared money). All participants were then compensated with a snack and invited to leave their e-mail address to be entered into a lottery to receive the calendar of their choice.

\section{Results and Discussion}

Manipulation Check. We first examined participants' responses to the manipulation check item. As expected, there was a significant difference such that those in the joint condition perceived the money in the bag as more shared $(M=3.42, S D=1.37)$ than those in the separate condition $(M=2.71, S D=1.29), t(65)=2.21, p=.031$.

Hedonic versus Utilitarian Product Choice. We next examined whether the money one used (separate vs. joint) affected the choice between the two calendars. Consistent with our predictions, participants that used joint funds were more likely to choose the university calendar $(55.9 \%)$ than those that used separate funds $(32.4 \%), \chi^{2}=3.82, p=.051$. 
Controlling for Individual Differences. To control for the measured covariates, we ran a binary logistic regression predicting the choice of product while including dummy variables for whether or not their partner was present when they made the decision, and whether they currently hold a joint account with their partner. As additional controls, we also included gender, age, and relationship length. Holding the covariates fixed, we examined the odds ratio, which represents the odds that an outcome will occur given a treatment, compared to the odds that an outcome will occur in the absence of that treatment. In this case, an odds ratio of 1 would indicate no difference between the joint and separate conditions, while an odds ratio greater than 1 would indicate that those in the joint condition were more likely to choose the utilitarian product. The results displayed in Table 1 demonstrate that the odds of choosing the university calendar (utilitarian product) were significantly higher for participants using joint funds, compared to those using separate funds $(\mathrm{OR}=2.90,95 \% \mathrm{CI}=1.00,8.38)$.

\section{Study 2: Mug Study}

The results from study 1 provide initial support for hypothesis 1 in the field, where participants are incentivized with real product choices, by showing that those spending with joint (vs. separate) money are more likely to choose utilitarian products over hedonic ones. In study 2, we provide additional evidence for hypothesis 1 by recruiting couple members that have access to both separate and joint accounts, and randomly assigning them to consider spending from one (separate or joint). This formulation of the independent variable eliminates the issues that arise when examining windfalls, as individuals perceive windfalls differently than personal income (Levav \& McGraw, 2009).

Study 2 used a single-factor between-subjects design where the type of account one was asked to consider spending from was manipulated (separate vs. joint). The dependent variable 
was the participants' choice between a hedonic and utilitarian product. We predicted that individuals spending from their joint (vs. separate) account would be more likely to choose the utilitarian product over the hedonic one (hypothesis 1).

\section{Product Pretest}

The purpose of this pretest was once again to ensure that one of the products presented to participants was indeed perceived as hedonic, while the other product was perceived as utilitarian. Sixty-two students $\left(45 \%\right.$ male, $\left.M_{\text {age }}=19.44\right)$ enrolled in an introductory marketing course completed this pretest as a favor to the instructor. They saw a picture of two mugs placed side by side: a mug to consume beer (the hedonic product) and a mug to consume coffee (the utilitarian product). To ensure that the products were equally attractive, both mugs prominently displayed the name and logo of the university on the front, and the university's fight song on the back.

All participants read the definition of hedonic and utilitarian products; we used the same definitions given to the raters in study 1 . They then rated how hedonic and utilitarian the mugs were (from $1=$ not at all, to $7=$ very much). In addition, they indicated how much they liked the two mugs (on a scale from 0-100).

As expected, paired-samples t-tests revealed that participants perceived the beer mug $(M$ $=5.90, S D=1.14)$ to be significantly more hedonic than the coffee mug $(M=3.40, S D=1.32)$, $t(61)=11.48, p<.001$, and the coffee $\operatorname{mug}(M=6.03, S D=1.17)$ to be significantly more utilitarian than the beer mug $(M=3.95, S D=1.61), t(61)=-8.62, p<.001$. There was no significant difference in the degree to which participants reported liking the beer mug $(M=$ $72.53, S D=20.33)$ or the coffee mug $(M=67.71, S D=21.86), t(61)=1.19, p=.24$, suggesting that one product was not strongly preferred over the other. 


\section{Participants and Procedure}

The study was run at a private university in the mid-west United States the Friday before a home football game. One of the study authors and four research assistants set up a table in the student union. A sign was used to attract and recruit participants in committed romantic relationships to take part in the study. After approaching the table, one of the research assistants asked participants if they had access to both separate and joint bank accounts with their partner. If not, they were told they were ineligible for the study and given a small candy. Otherwise, they were handed a one-page response sheet to complete, and told that they needed to complete it in order to buy one of the products on the table. If both couple members approached the table, only one was allowed to participate. Over the course of 8 hours, 148 participants $\left(55 \%\right.$ male, $M_{\text {age }}=$ 48.74) completed the study.

The response sheet was used to randomly assign participants to either the separate or joint account condition by asking them to remove from their wallet or purse either their separate bank account card, or their joint bank account card. After showing this card to the research assistant, they were told that they would be using this card to buy one of the products on the table (the beer mug or the coffee mug), being sold at the same price. If a participant did not have the requested card in their purse or wallet, they were told to consider for the sake of the task that they did have this card; a research assistant noted all participants that did not have the requested card so that this could be controlled for in the subsequent analysis. We also measured gender, age, marital status, relationship length, whether one thought the two products should be sold at a similar price, whether one's partner was present at the time of the decision, and if so, whether the decision was discussed with one's partner. After making their choice, all participants received their chosen product as compensation, and were instructed not to disclose to other participants 
that they received the mug without paying for it. For this reason, the research assistants asked all participants to step away from the table to receive their compensation so that other participants could not observe this transaction.

\section{Results and Discussion}

Hedonic versus Utilitarian Product Choice. We first examined whether the bank account card one used (separate vs. joint) affected the choice between the two mugs. Consistent with our predictions, participants that were asked to spend from their joint account were more likely to choose the coffee mug $(47.3 \%)$ than those asked to spend from their separate account $(34.6 \%), \chi^{2}=4.35, p=.037$

Controlling for Individual Differences. To control for the measured covariates, we ran a binary logistic regression predicting the choice of product while including dummies for whether or not participants thought the two mugs were sold at a similar price, whether or not they showed their bank card to the experimenter, and whether or not their partner was present when they made the decision. As additional controls, we also included gender, age, and relationship length. We provide the results in Table 2. Holding the covariates fixed, the odds of choosing the coffee mug (utilitarian product) were significantly higher for participants using their joint account compared to those using their separate account $(\mathrm{OR}=2.31,95 \% \mathrm{CI}=1.17$, 4.57).

The results from study 2 are consistent with those found in study 1, and provide further support for hypothesis 1 , with participants using their actual bank accounts to motivate their decisions. Thus, the results from both studies converge to support the hypothesis that those spending from a joint (vs. a separate) account are more likely to choose utilitarian products over hedonic ones. We provide evidence for the mechanism driving this effect in study 3. 


\section{Study 3: Clothes Study}

In study 3, we recruited participants from Amazon's Mechanical Turk (MTurk), and as in study 2 , randomly assigned them to consider spending from their separate or joint bank account. As it has been demonstrated that a large proportion of respondents in paid MTurk studies claim a false identity, ownership, or activity in order to qualify for a study, we followed one of the recommended procedures to recruit participants that involves a two-survey process, first asking respondents to identify their characteristics when there is no motive to deceive, and then limiting the second survey to those who passed this screen (Sharpe Wessling, Huber, \& Netzer, 2017). We first posted a pre-screen as a pre-requisite to participate in the study. Only participants who indicated that they were in a committed romantic relationship, and currently have access to both separate and joint bank accounts with their partner, advanced to the actual study. Participants could not complete the pre-screen more than once, and we included eight filler items (gender, age, race, etc.) to prevent participants from determining what we were screening for.

The objective of study 3 was to provide evidence for the underlying mechanism of the need to justify spending to one's partner, rather than to oneself. Study 3 used a single-factor between-subjects design where the type of account was manipulated (separate vs. joint). Participants were provided with a choice between a hedonic and utilitarian product, and this choice served as our main dependent variable. We also measured the extent to which participants felt the need to justify their choice to their partner and to themselves. Consistent with our results from studies 1 and 2, we predicted that individuals who considered spending from a joint (vs. a separate) account would be more likely to choose the utilitarian product over the hedonic one (hypothesis 1). We also predicted that the need to justify spending to one's partner, rather than the need to justify spending to oneself, would mediate this effect (hypothesis 2). 


\section{Participants and Procedure}

A total of 297 participants from MTurk $\left(52.5 \%\right.$ male, $\left.M_{\text {age }}=35.23\right)$ were paid 50 cents to complete this study. Participants were randomly assigned to an account condition (separate account vs. joint account), and informed they would complete a task on how they manage and spend their money.

Depending on their condition, participants were told they would be using either their joint or separate bank card. They read the following: "Please imagine you are out shopping by yourself. You only have your joint [separate] bank card with you to make purchases, as you left your other cards at home." Participants were then told: "You are shopping for some new clothes, and you find two different options that you like. The first option would be something you would wear to fun, social occasions (i.e., clothes for fun). The second option is something you would wear to work (i.e., clothes for work). Both options cost $\$ 75$, and as you are on a budget, you can only choose one of them."

Participants then made a binary choice between the hedonic or utilitarian product. Participants also indicated the strength of their preference using a sliding scale $(0=$ definitely would buy clothes for fun, 100 = definitely would buy clothes for work). Participants next indicated the degree to which they felt they needed to justify their purchase decision to their partner by indicating their extent of agreement $(1=$ not at all, $7=$ very much $)$ with an item adapted from Sela et al. (2009): "When I was making this decision, I felt the need to justify the choice to my partner." In addition to our proposed mechanism, we also tested a potential alternative mechanism - that individuals spending from a joint account feel the need to justify purchases to themselves. Therefore, participants also indicated their extent of agreement with the following: "When I was making this decision, I felt the need to justify the choice to myself." 


\section{Results and Discussion}

Hedonic versus Utilitarian Product Choice. We first examined product choice. As expected, participants spending from the joint account were more likely to choose the clothes for work $(74.7 \%)$ than those spending from the separate account $(60.5 \%), \chi^{2}=6.77, p=.009$. The results for preference strength follow the same pattern as choice share, with participants spending from the joint account more strongly preferring clothes for work over clothes for fun $\left(M_{\text {joint }}=\right.$ $69.35, S D_{\text {joint }}=28.31$ vs. $\left.M_{\text {sep }}=58.52, S D_{\text {sep }}=31.77\right), t(295)=3.11, p=.002$.

Need for Justification. To understand the role of the need for justification, we examined the responses to the question on the perceived need to justify spending to one's partner. As expected, those spending from the joint account experienced a greater need to justify spending to their partner $(M=4.09, S D=1.99)$ than those spending from the separate account $(M=3.27, S D$ $=2.09), t(295)=3.47, p=.001$. To examine whether the need to justify spending to one's partner drives the strength of utilitarian product preferences, we conducted a mediation analysis (Hayes, 2013). A bootstrap sample with 5,000 draws was administered to examine the conditional indirect effect. The results indicate mediation, as the $95 \%$ confidence interval excludes zero $(.85,5.03)$. In other words, the increased need to justify spending to one's partner that is experienced among individuals who spend from a joint account explains their preference for utilitarian products over hedonic ones.

To rule out the alternative explanation that the effect is driven by the need to justify spending to the self, we conducted a multiple mediation analysis, where we entered both the need to justify spending to one's partner and the need to justify spending to oneself as mediators in the same model. Once again, the results indicated mediation of the need to justify spending to 
one's partner $(1.04,5.46)$, but not the need to justify spending to oneself $(-2.32,0.29)$. For the regression coefficients, please refer to Figure 1.

These results support the hypothesis that, compared to spending from a separate account, spending from a joint account causes individuals to prefer utilitarian products over hedonic ones (hypothesis 1), and that this difference in product preference is driven by an increased need to justify spending to one's partner (hypothesis 2). In study 4, we provide additional support for our proposed mechanism by directly manipulating the ease with which a hedonic product can be justified.

\section{Study 4: Massage Study}

The objective of study 4 is to shed further light on our proposed psychological mechanism by demonstrating an important situation where the effect of account type on product purchase patterns disappears: when hedonic consumption is easily justifiable. Prior research indicates that the presence of a price discount makes hedonic products easier to justify (Cavanaugh, 2014; Mishra \& Mishra, 2011). Therefore, we hypothesize that those spending from a joint account will be more likely to choose hedonic products when they are sold at a discounted (vs. regular) price (hypothesis 3).

Study 4 thus used a single-factor between-subjects design where the price of a hedonic product (in this case, a massage at a luxury day spa) was manipulated (regular price $\$ 100$ vs. regular price $\$ 70$ vs. discounted price $\$ 70)$. We once again followed recommended procedures to recruit participants (Sharpe Wessling et al., 2017) by first posting a pre-screen as a pre-requisite to participate. In addition to eight filler items, we included a bank account status item that was used to determine participant eligibility; only participants who indicated they had access to at least one joint bank account with their partner advanced to the actual study. 
Participant likelihood of purchasing the massage was the key dependent variable. We predicted that when the massage was sold at a $30 \%$ discounted price of $\$ 70$, those spending from a joint account would be more likely to purchase the massage, than when it was sold at either a $\$ 70$ or $\$ 100$ regular price. We included a $\$ 70$ regular price condition, to ensure that our results were being driven by the discount itself, rather than the total amount of financial resources required to make the purchase. We also included a $\$ 100$ regular price condition, to ensure that our results were not being driven by differences in quality perceptions induced by different prices (Gneezy, Gneezy, \& Lauga, 2014; Rao \& Monroe, 1989), as the discounted massage would regularly be priced at $\$ 100$.

\section{Product Pretest}

The purpose of this pretest was twofold. First, we wanted to ensure that our price manipulation successfully shifted participants' perception of the ease of justification. Second, we wanted to ensure that participants viewed the product to be purchased as hedonic. Two hundred and ninety-nine participants from MTurk $\left(49 \%\right.$ male, $\left.M_{\text {age }}=36.9\right)$ were paid 50 cents to complete this pretest. Participants were randomly assigned to a price condition (regular price $\$ 100$ vs. regular price $\$ 70$ vs. discounted price $\$ 70$ ).

Those in the regular price $\$ 100$ condition read the following: "You are thinking about getting a massage at a massage parlor in town called 'Therapeutic Indulgence Luxury Day Spa.' A 60-minute massage is priced at $\$ 100$." Those in the regular price $\$ 70$ condition read: "You are thinking about getting a massage at a massage parlor in town called 'Therapeutic Indulgence Luxury Day Spa.’ A 60-minute massage is priced at \$70.” Those in the discounted price $\$ 70$ condition read: "You are thinking about getting a massage at a massage parlor in town called 'Therapeutic Indulgence Luxury Day Spa.' It is running a special promotion, with 60-minute 
massages priced at only $\$ 70$; this represents a $30 \%$ discount, as these massages are normally priced at $\$ 100 . "$

All participants then indicated the degree to which they felt they could justify this purchase if they used their joint bank account $(1=$ not at all, $7=$ very much $)$ by answering the following two questions: 1) Would you struggle to justify this purchase to your partner? 2) Would you be concerned that your partner might not approve of this purchase? To aid interpretation, we reverse-coded both of these items, and averaged the responses to create an ease of justification index (Cronbach's alpha $=.87)$.

Lastly, all participants read the same definitions of hedonic and utilitarian products that were provided to participants in the study 1 and 2 pretests. They then rated how hedonic and utilitarian $(1=$ not at all, $7=$ very much $)$ a massage would be if they received it at Therapeutic Indulgence Luxury Day Spa.

Consistent with the first goal of this pretest, the results revealed that those who considered purchasing a massage at a discounted price of $\$ 70$ felt that the purchase was easier to justify $(M=4.30, S D=2.04)$ than those who considered purchasing a massage at a regular price of $\$ 100(M=3.43, S D=1.98), t(296)=3.06, p=.002$, and a regular price of $\$ 70(M=3.71, S D$ $=1.97), t(296)=2.07, p=.039$. There was no significant difference in the anticipated ease of justification amongst those in the $\$ 100$ regular and $\$ 70$ regular price conditions, $t(296)=.99, p=$ .32 .

Consistent with the second goal of this pretest, a paired-samples t-test revealed that participants perceived a massage at Therapeutic Indulgence Luxury Day Spa to be significantly more hedonic $(M=5.96, S D=1.24)$ than utilitarian $(M=3.35, S D=1.93), t(298)=16.77, p<$ .001 . 


\section{Participants and Procedure}

Three hundred and ten participants from MTurk $\left(59 \%\right.$ male, $\left.M_{\text {age }}=34.7\right)$ were paid 50 cents to complete the actual study. All participants were randomly assigned to one of the three price conditions from the pretest (regular price $\$ 100$ vs. regular price $\$ 70$ vs. discounted price \$70). Then, they all read: "Using the joint bank account that you hold with your significant other, please indicate how likely you would be to purchase this massage." They responded on a 1-7 scale $(1=$ not at all likely, $7=$ very likely $)$.

\section{Results and Discussion}

The results reveal the predicted main effect of price, $F(2,307)=3.63, p=.028$. Those in the $\$ 70$ discounted price condition were more likely to purchase the massage $(M=4.72, S D=$ 1.80) than those in the $\$ 70$ regular price condition $(M=4.08, S D=2.06), t(307)=2.27, p=.024$. Similarly, those in the $\$ 70$ discounted price condition were more likely to purchase the massage than those in the $\$ 100$ regular price condition $(M=4.05, S D=2.14), t(207)=2.40, p=.017$. Those in the regular price conditions (\$70 vs. \$100) did not differ significantly from one another, $t(207)=.11, p=.91$.

Together, these results suggest that when a hedonic product can be easily justified, in this case because of a price discount, those spending from a joint account become more likely to make the purchase (hypothesis 3). Further, keeping the product the same and only manipulating the price provided to participants, underscores the importance of the ease with which hedonic purchases can be justified to one's partner.

\section{Study 5: Joint versus Separate Accounts and Real Spending Behavior}

Studies 1-3 demonstrated that those spending from a joint (vs. a separate) bank account are more likely to choose utilitarian (vs. hedonic) products, and study 4 showed that this effect 
can be attenuated when the product is easier to justify. The aim of study 5 is to demonstrate the real-world consequences that the effect of joint accounts on consumption choices may have, on aggregate, over time. We thus investigated the correlational relationship between spending from a joint or separate bank account, and the actual amount spent on utilitarian and hedonic products. To do this, we partnered with a retail bank to collect detailed transaction data from customers who either spend from an individual account, or a joint account with their partner. The data included information on what products each person purchased over a twelve-month period, and the amount spent on these products. Taking advantage of this unique data set, we investigated whether consumers in a committed romantic relationship buy more utilitarian (and less hedonic) products when spending from an account that is joint rather than separate (hypothesis 1).

An important confound in using this field data is that people who choose to spend from a joint account with their partner tend to differ on a number of demographics from those who choose to spend from a separate account. Descriptive statistics for these two groups can be found in the Methodological Details Appendix (MDA 3). Therefore, we use a regression analysis to demonstrate that the main effect of spending from a joint (vs. a separate) account on product purchase still holds after controlling for these differences.

\section{Participants and Procedure}

Customers of a large national bank in the United Kingdom were recruited by e-mail in late 2014 to complete a survey about their financial attitudes and behaviors. We received data from 912 individuals who completed the survey and agreed to have their responses linked to their bank-reported financial data from the previous 12 months. We selected only those customers who reported that their checking account with the bank was their primary account, and who indicated that they were in a long-term relationship or married $(n=396)$. Of the 396 
individuals, $281\left(45 \%\right.$ male, $\left.M_{\mathrm{age}}=36.55\right)$ held a separate (single-user $)$ account, and $115(47 \%$ male, $M_{\text {age }}=44.57$ ) held a joint account.

The records for these customers included detailed data of all transactions from their checking account over a period of 12 months. All data are from debit cards linked to customers' checking accounts, which are the most common form of payment in the United Kingdom (UKCards, 2017). Purchases were automatically grouped by the bank into categories, such as supermarkets, clothes, and home insurance. We excluded categories that did not allow for a meaningful interpretation (e.g., "unallocated" or "services other"), or in which there were fewer than 100 transactions. The mean number of transactions for each category was $4,178.03(S D=$ 9,000.96), and the mean amount spent on each category was $£ 112,302.20(S D=166,583.5)$.

Rating Spending Categories. Twenty-five British participants from an online panel called Prolific Academic (44\% male, $M_{\text {age }}=36.08$ ) were paid $£ 4(\$ 6)$ to rate the degree to which they perceived the spending categories used in our analysis to be hedonic or utilitarian. We chose British raters to ensure that the spending categories were familiar. All raters read the following: "Hedonic goods are those that are pleasant and fun, i.e., something that is enjoyable and appeals to your senses. Utilitarian goods are useful, practical, or functional, i.e., something that helps you achieve a goal. It is possible for a category to be equally hedonic and utilitarian. It is also possible for a category to be higher in one quality than it is in the other." After reading this information, they rated each category on how hedonic and utilitarian they felt it was (from $1=$ not at all, to $9=$ extremely).

Their responses were averaged to create a hedonic and utilitarian rating for each spending category. We then classified each category as either hedonic or utilitarian by comparing the means between the two ratings using a paired samples t-test. For example, people rated Life 
Insurance as significantly more utilitarian $(M=7.2, S D=1.87)$ than hedonic $(M=2.48, S D=$ $1.47, t(24)=-8.19, p<.001)$, and this category was therefore classified as utilitarian. The Methodological Details Appendix (MDA 4-5) provides a summary of the ratings for the categories included in the analysis, as well as the total number and amount of transactions from the overall spending totals.

\section{Results and Discussion}

For each customer, we calculated their total spending on hedonic and utilitarian categories over the 12-month period. We next ran multiple linear regression models predicting hedonic and utilitarian spending as a function of their joint account status and a range of controls. These included relevant demographic and financial variables that may also influence spending on hedonic and utilitarian categories, such as age, gender, income, whether the participant has any children, or is married. Because joint accounts capture the spending of two people, while single accounts capture the spending of one, the analysis predicts spending on hedonic or utilitarian purchases while controlling for overall expenditure across all categories. We present the results of hedonic spending first, followed by utilitarian spending.

Hedonic Spending. The results presented in Table 3 suggest that individuals who used a joint (vs. a separate) bank account spent significantly less of their money on hedonic products ( $b$ $\left.=-489.57, t=-2.96, \mathrm{CI}_{95} \%[-814.31,-164.82]\right)$. This means that those spending from a joint account spent on average $£ 490$ less over the year on hedonic purchases compared to those spending from a separate account, and these results remain similar after including a range of financial and demographic covariates (Model 2). As the measure of hedonic spending is positively skewed, we re-ran Model 2 using bootstrap methods 5,000 times, and found that the 
bias-corrected bootstrap $95 \%$ confidence interval does not contain zero $\left(\mathrm{CI}_{95 \%}=[-851.55\right.$, 32.99]).

The regression results also highlight the association between hedonic spending and other variables. For example, each additional $£ 100$ in overall spending is associated with a $£ 7.39$ increase in hedonic spending, and those who are older or who have children spent less on hedonic goods on average. Importantly, the effect of using a joint account on hedonic spending remains significant when controlling for these other variables.

Utilitarian Spending. The results in Table 4 show that after controlling for the same set of covariates used in the previous analysis, individuals who used a joint (vs. a separate) bank account spent more on utilitarian products $\left(b=1129.25, t=3.46, \mathrm{CI}_{95 \%}[486.84,1771.65]\right)$. Those spending from a joint account spent on average $£ 1129$ more over the year on utilitarian purchases compared to those spending from a separate account. Once again, we re-ran the full model using bootstrap methods 5,000 times, and the bias-corrected bootstrap 95\% confidence interval did not contain zero, $\left(\mathrm{CI}_{95 \%}=[342.00,1670.41]\right)$.

As an alternative approach to analyzing these data, we also employed a regression model using the proportional amount a person spent on hedonic products compared against their spending on utilitarian products. To calculate this ratio, we divided each customer's total hedonic spending by their total utilitarian spending. Controlling for the same financial and demographic characteristics, and using bootstrap methods 5,000 times to account for the skewed ratio variable, the regression analysis again confirms that individuals who used a joint (vs. a separate) bank account spent a smaller proportion of their money on hedonic relative to utilitarian categories $(b$ $=-.30, t=-2.12,95 \% \mathrm{CI}[-0.57,-0.02])$. Using real bank accounts and spending, these results are consistent with our predictions. 
Finally, we also analyzed the data for spending categories that could not clearly be classified by the independent raters as hedonic or utilitarian. After controlling for the same set of covariates used in the previous analysis, we find (as predicted) that individuals who used a joint bank account were not significantly more or less likely to spend on these products $(b=118.57, t$ $=1.35,95 \%$ CI $[-53.55,290.68])$, compared to those who used a separate account. These additional regression model results are provided in the Methodological Details Appendix (MDA $6)$.

\section{General Discussion}

In this research, we find that couple members' use of joint or separate bank accounts influences their consumption decisions because spending from a joint account results in an increased need to justify spending to one's partner. In line with this mechanism, our results consistently demonstrate that those spending from a joint account are more likely to choose a utilitarian (vs. a hedonic) option, than those spending from a separate account. Study 1 illustrates our basic effect in the field, by randomly assigning participants to spend separate or shared money with their partner. Study 2 provides additional causal evidence for this main effect in the field, examining a real product choice where participants are randomly assigned to use a bank account they actually possess. The next two studies provide evidence for why spending from a joint (vs. a separate) bank account influences consumption. Study 3 demonstrates that the need to justify spending to one's partner, rather than the need to justify spending to oneself, mediates the effect of account type on product choice. Study 4 demonstrates that making hedonic products easier to justify attenuates the effect. Lastly, analyzing over 160,000 bank transactions, study 5 provides real-world correlational evidence that those spending from a joint account spend more money on utilitarian (vs. hedonic) products, compared to those spending from a separate account. 
We took great care to ensure that our main effect was robust and generalizable. Of note, we rely on several populations to test our hypotheses: participants attending a college football game in the mid-west US in studies 1 and 2, participants from MTurk in studies 3 and 4, and participants from the UK in study 5. Across all samples, we find consistent support for our hypothesis that spending from a joint (vs. a separate) bank account alters consumption consequences.

\section{Contributions}

This research makes several theoretical contributions by furthering our understanding of consumer behavior in relationship contexts. Recent reviews of the literature suggest that, despite the numerous ways in which close relationships with romantic partners shape consumption, the topic is surprisingly understudied within the consumer behavior literature (Cavanaugh, 2016; Gorlin \& Dhar, 2012; Simpson et al., 2012). That the studies reveal sizeable differences in the amount of money spent over time (study 5), as well as in real choice behavior (studies 1 and 2), underscores the importance of studying financial decision-making in relationship contexts. By examining the conditions under which couple members are more likely to consider the need to justify their spending, and how their partner will feel about a purchase, the current findings provide insights into how couple member's consumption decisions can differ from single individuals. Although past research has illustrated the importance of justification when choosing utilitarian products, these choices have typically only impacted the individual consumer (Cavanaugh, 2014; Khan \& Dhar, 2006; Shafir et al., 1993). We thus extend past work by examining the importance of justification when choices affect both members of the couple, as any spending reduces the total amount of money available for the couple to utilize in the future. Our work also contributes to an emerging stream of research on financial decision- 
making in couples. Previous work in this area has focused on financial decisions made by couple members in tandem (Dzhogleva \& Lamberton, 2014; Olson \& Rick, 2015), or on joint consumption decisions that are made for both couple members to consume together (Etkin, 2016). We build on this work by showing that how couples choose to manage their finances affects decisions they make in the absence of their partner, and extends beyond products which both of them will consume to affect individual consumption preferences. We feel that this is an important extension to make, given the number of decisions that couple members make in the absence of their partner each day (Belch \& Willis, 2002; Cunningham \& Green, 1974). In study 2, for instance, $72 \%$ of participants attended the football game without their significant other and thus made a purchase decision in the absence of their partner, highlighting the pervasiveness of such decisions and why they are important to study.

From a practical perspective, our research also sheds light on the advantages and disadvantages of pooling finances. One potential advantage of choosing to maintain a joint account is that it constrains unnecessary spending. At a time when high levels of hedonic consumption have been described as a major problem for modern society (De Graaf, Wann, \& Naylor, 2005), this research highlights a potential psychological mechanism to inhibit such spending. Past research demonstrates that consumers are willing to pay for products and services that act as commitment devices to control their spending (Bryan, Karlan, \& Nelson, 2010). In a similar vein, products or services could be created to increase the need to justify spending. Our work suggests that reminders of the joint nature of one's bank account, through an automatic text message from one's partner or a picture of one's partner on the physical credit card, could make the need for justification more salient and thereby curb unnecessary expenses.

On the other hand, a potential disadvantage of pooling finances is the effect it might have 
on consumer happiness, an area of research which has received considerable attention over the past decade (Bhattacharjee \& Mogilner, 2014; Mogilner, Aaker, \& Kamvar, 2012). This research has shown that hedonic products, which are often experiential, tend to be associated with increased happiness (Gilovich, Kumar, \& Jampol, 2015; Van Boven \& Gilovich, 2003). For this reason, it may be the case that pooling finances could cause couples to consistently spend their money in ways that decrease happiness over time. Whether couples who pool their finances, or keep them separate, are happier in their relationship remains unclear and is worthy of future investigation.

\section{Caveats and Calls for Future Research}

This research was inspired by a lack of empirical work examining the psychological effects of spending from joint (vs. separate) bank accounts. Our findings and methods, however, are not without their limitations. The most important challenge in this research is limiting the threat of endogeneity. Although we have attempted to generate evidence for a causal chain of inference through the use of controlled experiments, where we attempted to rule out alternative explanations through random assignment, we acknowledge that such stylized experiments (e.g., using bags of nickels to represent shared accounts) may not accurately capture the complex interdependent decision of purchasing from these types of accounts. Furthermore, in the real world, the decision of whether to maintain joint or separate bank accounts may be influenced by a range of unmeasured characteristics of the individuals or their environment, highlighting the need for additional research on this topic.

In addition, our research poses several other intriguing questions that merit follow-on work. One such example is the potentially moderating role of household income. Although we took great care to ensure that our main effect replicates across both relatively low-priced (e.g., 
mugs) and high-priced products (e.g., clothes), it may be the case that after a certain price threshold, expensive products become very difficult to justify (regardless of product category). However, this threshold is likely to differ based on the combined income and wealth of the couple, as what may seem like a trivial purchase for one couple, may be a large expense for another. Therefore, future research that elucidates the relationship between using joint (vs. separate) bank accounts, spending on high-priced utilitarian products, and the financial wealth of the couple (both objective and subjective) merits further investigation.

Another area worthy of future investigation is whether our findings extend beyond the scope of romantic relationships to, for instance, the workplace and business partnerships. More specifically, do individuals spending from a shared account that they hold with their business partner or employer, also experience an increased need to justify their spending? We expect that the extent to which individuals feel the need to justify their expenditures within these workplace contexts will depend on a variety of factors; including the strength of their relationships with other partners/employees, the size and success of the business, and the degree of perceived ownership. For example, we would expect that someone working in a family business is more likely to experience an increased need to justify what they buy, compared to someone working within a large corporation. Although past research has examined spending from company expense accounts, the bulk of this research has focused on unethical decision-making, such as whether or not to over-claim on the company account (Betz, O'Connell, \& Shepard, 1989; Ferrell, Weaver, Taylor, \& Jones, 1978; Ruegger \& King, 1992). Future research that elucidates ethical spending from either a separate (vs. a joint) business account might provide new practically relevant insights for managers.

Finally, our findings highlight how spending from a separate versus joint account affects 
one's preference for utilitarian or hedonic products. It is important to note, however, that the increased need for justification experienced among those spending from a joint account is likely to affect other types of financial decisions. For example, spending from a joint (vs. a separate) account may increase the likelihood of purchasing material products over experiential ones; materialistic purchases last longer than experiential ones (Tully, Hershfield, \& Meyvis, 2015), potentially making them easier to justify. Extending beyond spending decisions, those with joint accounts may be less likely to donate money to charity or to political causes than those with separate accounts. Employees working at non-profit organizations claim that encouraging donations is their single most important challenge (West, 2004), and one reason may be the difficulty in justifying such spending to others. With this in mind, we hope to encourage future research on the many potential consequences of spending from separate versus joint accounts. While shared lives often necessitate sharing money, we encourage readers to consider whether joint accounts may inadvertently influence how that shared money is spent. 


\section{References}

Belch, M. A., \& Willis, L. A. (2002). Family Decision at the Turn of the Century: Has the Changing Structure of Households Impacted the Family Decision-Making Process? Journal of Consumer Behaviour, 2(2), 111-124.

Betz, M., O'Connell, L., \& Shepard, J. M. (1989). Gender Differences in Proclivity for Unethical Behavior. Journal of Business Ethics, 8(5), 321-324.

Bhattacharjee, A., \& Mogilner, C. (2014). Happiness from Ordinary and Extraordinary Experiences. Journal of Consumer Research, 41(1), 1-17.

Brice, J., Buck, N., \& Prentice-Lane, E. (2002). British Household Panel Survey User Manual Volume A: Introduction, Technical Report, and Appendices: Colchester: University of Essex.

Bryan, G., Karlan, D., \& Nelson, S. (2010). Commitment Devices. Annual Review of Economics, 2(1), 671-698.

Burns, A. C. (1977). Husband and Wife Purchase Decision-Making Roles: Agreed, Presumed, Conceded, and Disputed. Advances in Consumer Research, 4, 50-55.

Burns, A. C., \& Granbois, D. H. (1977). Factors Moderating the Resolution of Preference Conflict in Family Automobile Purchasing. Journal of Marketing Research, 14, 77-86.

Cavanaugh, L. A. (2014). Because I (Don't) Deserve It: How Relationship Reminders and Deservingness Influence Consumer Indulgence. Journal of Marketing Research, 51(2), 218-232.

Cavanaugh, L. A. (2016). Consumer Behavior in Close Relationships. Current Opinion in Psychology, 10, 101-106.

Cheal, D. (1993). Changing Household Financial Strategies: Canadian Couples Today. Human Ecology, 21(2), 197-213.

Cunningham, I. C. M., \& Green, R. T. (1974). Purchasing Roles in the US Family, 1955 and 1973. The Journal of Marketing, 38, 61-64.

Davis, H. L. (1970). Dimensions of Marital Roles in Consumer Decision Making. Journal of Marketing Research, 168-177.

Davis, H. L. (1971). Measurement of Husband-Wife Influence in Consumer Purchase Decisions. Journal of Marketing Research, 305-312. 
Davis, H. L. (1976). Decision Making Within the Household. Journal of Consumer Research, 2(4), 241-260.

De Graaf, J., Wann, D., \& Naylor, T. H. (2005). Affluenza: The All-Consuming Epidemic: Berrett-Koehler Publishers.

Dolan, K., \& Dolan, D. (1993). Follow These Rules to Avoid Family Fights Over Money. Money, 22(7), 23-23.

Dzhogleva, H., \& Lamberton, C. P. (2014). Should Birds of a Feather Flock Together?

Understanding Self-Control Decisions in Dyads. Journal of Consumer Research, 41(2), 361-380.

Etkin, J. (2016). Choosing Variety for Joint Consumption. Journal of Marketing Research, 53, 1019-1033.

Ferrell, O. C., Weaver, K. M., Taylor, J. W., \& Jones, R. M. (1978). Ethical Beliefs of Marketing Managers. The Journal of Marketing, 42(3), 69-73.

Gilovich, T., Kumar, A., \& Jampol, L. (2015). A Wonderful Life: Experiential Consumption and the Pursuit of Happiness. Journal of Consumer Psychology, 25(1), 152-165.

Gneezy, A., Gneezy, U., \& Lauga, D. O. (2014). A Reference-Dependent Model of the PriceQuality Heuristic. Journal of Marketing Research, 51(2), 153-164.

Gorlin, M., \& Dhar, R. (2012). Bridging the Gap Between Joint and Individual Decisions: Deconstructing Preferences in Relationships. Journal of Consumer Psychology, 22(3), 320-323.

Gourville, J. T., \& Soman, D. (1998). Payment Depreciation: The Behavioral Effects of Temporally Separating Payments from Consumption. Journal of Consumer Research, 25(2), 160-174.

Hayes, A. F. (2013). Introduction to Mediation, Moderation, and Conditional Process Analysis: A Regression-Based Approach: Guilford Press.

Heath, C., \& Soll, J. B. (1996). Mental Budgeting and Consumer Decisions. Journal of Consumer Research, 23(1), 40-52.

Hsee, C. K. (1995). Elastic Justification: How Tempting but Task-Irrelevant Factors Influence Decisions. Organizational Behavior and Human Decision Processes, 62(3), 330-337.

Kahneman, D., \& Tversky, A. (1984). Choices, Values, and Frames. American Psychologist, $39(4), 341$. 
Khan, U., \& Dhar, R. (2006). Licensing Effect in Consumer Choice. Journal of Marketing Research, 43(2), 259-266.

Kivetz, R., \& Simonson, I. (2002). Self-Control for the Righteous: Toward a Theory of Precommitment to Indulgence. Journal of Consumer Research, 29(2), 199-217.

Lerouge, D., \& Warlop, L. (2006). Why It Is So Hard to Predict Our Partner's Product Preferences: The Effect of Target Familiarity on Prediction Accuracy. Journal of Consumer Research, 33(3), 393-402.

Levav, J., \& McGraw, A. P. (2009). Emotional Accounting: How Feelings about Money Influence Consumer Choice. Journal of Marketing Research, 46(1), 66-80.

Mishra, A., \& Mishra, H. (2011). The Influence of Price Discount Versus Bonus Pack on the Preference for Virtue and Vice Foods. Journal of Marketing Research, 48(1), 196-206.

Mogilner, C., Aaker, J., \& Kamvar, S. D. (2012). How Happiness Affects Choice. Journal of Consumer Research, 39(2), 429-443.

Munsinger, G. M., Weber, J. E., \& Hansen, R. W. (1975). Joint Home Purchasing Decisions by Husbands and Wives. Journal of Consumer Research, 1(4), 60-66.

O'Curry, S., \& Strahilevitz, M. (2001). Probability and Mode of Acquisition Effects on Choices Between Hedonic and Utilitarian Options. Marketing Letters, 12(1), 37-49.

Olson, J. G., \& Rick, S. (2015). Managing Debt and Managing Each Other: The Interpersonal Dynamics of Shared Financial Decisions. SSRN Working Paper Series. Retrieved from http://papers.ssrn.com/sol3/papers.cfm?abstract_id=2637637

Pahl, J. (1995). His Money, Her Money: Recent Research on Financial Organisation in Marriage. Journal of Economic Psychology, 16(3), 361-376.

Prelec, D., \& Loewenstein, G. (1998). The Red and the Black: Mental Accounting of Savings and Debt. Marketing science, 17(1), 4-28.

Rao, A. R., \& Monroe, K. B. (1989). The Effect of Price, Brand Name, and Store Name on Buyers' Perceptions of Product Quality: An Integrative Review. Journal of marketing Research, 26, 351-357.

Ruegger, D., \& King, E. W. (1992). A Study of the Effect of Age and Gender Upon Student Business Ethics. Journal of Business Ethics, 11(3), 179-186.

Scheibehenne, B., Todd, P. M., \& Mata, J. (2011). Older but Not Wiser: Predicting a Partner's Preferences Gets Worse with Age. Journal of Consumer Psychology, 21(2), 184-191. 
Sela, A., Berger, J., \& Liu, W. (2009). Variety, Vice, and Virtue: How Assortment Size Influences Option Choice. Journal of Consumer Research, 35(6), 941-951.

Shafir, E., Simonson, I., \& Tversky, A. (1993). Reason-Based Choice. Cognition, 49(1-2), 11-36.

Sharpe Wessling, K., Huber, J., \& Netzer, O. (2017). MTurk Character Misrepresentation: Assessment and Solutions. Journal of Consumer Research, 44(1), 211-230.

Shefrin, H. M., \& Thaler, R. H. (1992). Mental Accounting, Saving, and Self-Control (G. Loewenstein \& J. Elster Eds.). Choice Over Time: Russell Sage Foundation.

Simpson, J. A., Griskevicius, V., \& Rothman, A. J. (2012). Consumer Decisions in Relationships. Journal of Consumer Psychology, 22(3), 304-314.

Soman, D., \& Lam, V. M. W. (2002). The Effects of Prior Spending on Future Spending Decisions: The Role of Acquisition Liabilities and Payments. Marketing Letters, 13(4), 359-372.

Strahilevitz, M. A., \& Myers, J. (1998). Donations to Charity as Purchase Incentives: How Well They Work May Depend on What You Are Trying to Sell. Journal of Consumer Research, 24(4), 434-436.

Sussman, A. B., \& O’Brien, R. L. (2016). Knowing When to Spend: Unintended Financial Consequences of Earmarking to Encourage Savings. Journal of Marketing Research, 53(5), 790-803.

Thaler, R. H. (1985). Mental Accounting and Consumer Choice. Marketing Science, 4(3), 199214.

Thaler, R. H. (1999). Mental Accounting Matters. Journal of Behavioral Decision Making, 12(3), 183-206.

Todorova, A. (2007). The Six Financial Mistakes Couples Make. Retrieved from https://www.key.com/html/couples-financial-planning-articles.html

Treas, J. (1993). Money in the Bank: Transaction Costs and the Economic Organization of Marriage. American Sociological Review, 723-734.

Tully, S. M., Hershfield, H. E., \& Meyvis, T. (2015). Seeking Lasting Enjoyment with Limited Money: Financial Constraints Increase Preference for Material Goods over Experiences. Journal of Consumer Research, 42(1), 59-75. 
UKCards. (2017). UK Card Payments Summary The UK Cards Association. http://www.theukcardsassociation.org.uk/wm_documents/UK\%20Card\%20Payments\%2 02017\%20-\%20Summary\%20FINAL.pdf.

Van Boven, L., \& Gilovich, T. (2003). To Do or to Have? That is the Question. Journal of Personality and Social Psychology, 85(6), 1193-1202.

Vogler, C., Brockmann, M., \& Wiggins, R. D. (2006). Intimate Relationships and Changing Patterns of Money Management at the Beginning of the Twenty-First Century. The British Journal of Sociology, 57(3), 455-482.

West, L. A. (2004). Non-Profits Face Funding Pressures. Journal of Accountancy, 198(3), 16. Zelizer, V. A. (1989). The Social Meaning of Money: "Special Monies". American Journal of Sociology, 95(2), 342-377. 
Table 1: Logistic Regression Model of Choice of Utilitarian Calendar by

Account Condition and Covariates

\begin{tabular}{ccccc}
\hline & \multicolumn{3}{c}{ Choosing Utilitarian Product } \\
\hline & $O R$ & $z$ & \multicolumn{2}{c}{ CI $_{95 \%}$} \\
\hline Joint Account Condition & 2.90 & $1.96^{*}$ & 1.00 & 8.38 \\
Partner Present & 0.49 & -0.91 & 0.11 & 2.26 \\
Owns Joint Account & 1.24 & 0.36 & 0.38 & 4.01 \\
Female & 2.47 & 1.63 & 0.83 & 7.31 \\
Age & 1.03 & 0.92 & 0.97 & 1.09 \\
Relationship Length & 1.02 & 0.61 & 0.96 & 1.08 \\
Intercept & 0.10 & $-1.92^{\dagger}$ & 0.01 & 1.05 \\
\hline
\end{tabular}

${ }^{\dagger} p<.1 .{ }^{*} p<.05, n=68$. Joint Account, Partner Present, Owns Joint Account and

Female are dummy variables $(=1$, otherwise 0$)$. Age and Relationship Length are in years. Odds Ratios reported. 
Table 2: Logistic Regression Model of Choice of Utilitarian Product by

Account Condition and Covariates

\begin{tabular}{ccccc}
\hline & \multicolumn{3}{c}{ Choosing Utilitarian Product } \\
\hline & $O R$ & $z$ & \multicolumn{2}{c}{ CI $_{95 \%}$} \\
\hline Joint Account Condition & 2.31 & $2.41^{*}$ & 1.17 & 4.57 \\
Similar Price & .89 & -.31 & .43 & 1.85 \\
Showed Card & .36 & -1.15 & .06 & 2.05 \\
Partner Present & 1.01 & 0.02 & .47 & 2.17 \\
Female & 1.03 & 0.08 & .51 & 2.06 \\
Age & 1.04 & $1.90^{\dagger}$ & .99 & 1.08 \\
Relationship Length & .98 & -1.19 & .94 & 1.02 \\
Intercept & .35 & -0.83 & .03 & 4.19 \\
\hline
\end{tabular}

${ }^{*} p<.1 . * p<.05, n=148$. Joint Account, Similar Price, Showed Card, Partner Present and Female are dummy variables (=1, otherwise 0). Age and Relationship Length are in years. Odds Ratios reported. 
Table 3: OLS Multiple Linear Regression Analysis of Hedonic Spending Predicted by Joint Account Status, Total Spending and Controls

\begin{tabular}{|c|c|c|c|c|c|c|c|c|}
\hline & \multicolumn{8}{|c|}{ Hedonic Spending } \\
\hline & \multicolumn{4}{|c|}{ Model 1} & \multicolumn{4}{|c|}{ Model 2} \\
\hline & $b$ & $t$ & \multicolumn{2}{|c|}{$\mathrm{CI}_{95 \%}$} & $b$ & $t$ & \multicolumn{2}{|c|}{$\mathrm{CI}_{95 \%}$} \\
\hline Joint Account & -489.57 & $-2.96 * *$ & -814.31 & -164.82 & -442.27 & $-2.58 * *$ & -779.02 & -105.52 \\
\hline Total Spending (£100) & 6.48 & $10.07 * * *$ & 5.21 & 7.74 & 7.39 & $7.77 * * *$ & 5.51 & 9.25 \\
\hline Has Child & & & & & -369.86 & $-2.36^{*}$ & -678.39 & -61.34 \\
\hline Married & & & & & 259.81 & 1.56 & -68.07 & 587.68 \\
\hline Male & & & & & 170.12 & 0.25 & -120.66 & 460.89 \\
\hline Age in Years & & & & & -18.46 & $-2.96^{* *}$ & -30.72 & -6.20 \\
\hline Savings (£100) & & & & & 0.01 & 0.1 & -0.24 & 0.27 \\
\hline Debts $(£ 100)$ & & & & & -1.27 & -1.51 & -2.92 & 0.38 \\
\hline Income $(£ 100)$ & & & & & -0.37 & -0.72 & -1.38 & 0.64 \\
\hline Intercept & 213.34 & $1.76^{\dagger}$ & -24.55 & 451.24 & 723.35 & $3.25 * *$ & 285.87 & 1160.82 \\
\hline$R 2$ adj & \multicolumn{4}{|c|}{.20} & \multicolumn{4}{|c|}{.22} \\
\hline \multicolumn{9}{|c|}{$\begin{array}{l}p<.1 . * p<.05, * * p<.01, * * * p<.001 . n=396 . \text { Joint Account, Male, Has Child, and Married } \\
\text { are dummy variables }(=1, \text { otherwise } 0 \text { ). Income (in units of } £ 100) \text { is the bank-reported monthly } \\
\text { average of credits to participants' checking accounts. Total Spending (in units of £100) is the } \\
\text { bank-reported monthly average of debits from participants'checking accounts across all } \\
\text { spending categories. Savings and Debts (in units of } £ 100 \text { ) are self-reported figures from the } \\
\text { survey. Age is in years calculated from date of birth records held by the bank. }\end{array}$} \\
\hline
\end{tabular}


Table 4: OLS Multiple Linear Regression Analysis of Utilitarian Spending Predicted by Joint Account Status and Controls

\begin{tabular}{|c|c|c|c|c|c|c|c|c|}
\hline & \multicolumn{8}{|c|}{ Utilitarian Spending } \\
\hline & \multicolumn{4}{|c|}{ Model 3} & \multicolumn{4}{|c|}{ Model 4} \\
\hline & $b$ & $t$ & \multicolumn{2}{|c|}{$\mathrm{CI}_{95 \%}$} & $b$ & $t$ & \multicolumn{2}{|c|}{$\mathrm{CI}_{95 \%}$} \\
\hline Joint Account & 1149.03 & $3.65 * * *$ & 529.90 & 1768.16 & 1129.25 & $3.46^{* * *}$ & 486.84 & 1771.65 \\
\hline Total Spending (£100) & 17.41 & $14.21 * * *$ & 14.99 & 19.82 & 20.50 & $11.31 * * *$ & 16.94 & 24.07 \\
\hline Has Child & & & & & 680.81 & $2.27^{\dagger}$ & 92.26 & 1269.37 \\
\hline Married & & & & & 88.19 & 0.28 & -537.28 & 713.65 \\
\hline Male & & & & & -252.11 & -0.89 & -806.81 & 302.59 \\
\hline Age in Years & & & & & -3.02 & -0.25 & -26.41 & 20.37 \\
\hline Savings (£100) & & & & & -0.42 & $-1.71^{\dagger}$ & -0.9 & 0.06 \\
\hline Debts (£100) & & & & & -1.14 & -0.71 & -4.29 & 2.02 \\
\hline Income $(£ 100)$ & & & & & -1.93 & $-1.97 *$ & -3.86 & -0.01 \\
\hline Intercept & 1898.30 & $8.23 * * *$ & 1444.75 & 2351.85 & 1955.16 & $4.25 * * *$ & 1050.71 & 2859.61 \\
\hline$R 2 a d j$ & \multicolumn{4}{|c|}{.39} & \multicolumn{4}{|c|}{.40} \\
\hline \multicolumn{9}{|c|}{$\begin{array}{l}p<.1 . * p<.05, * * p<.01, * * * p<.001 . n=396 . \text { Joint Account, Male, Has Child, and Married } \\
\text { are dummy variables }(=1, \text { otherwise } 0) \text {. Income (in units of } £ 100) \text { is the bank-reported monthly } \\
\text { average of credits to participants' checking accounts. Total Spending (in units of £100) is the } \\
\text { bank-reported monthly average of debits from participants' checking accounts across all } \\
\text { spending categories. Savings and Debts (in units of £100) are self-reported figures from the } \\
\text { survey. Age is in years calculated from date of birth records held by the bank. }\end{array}$} \\
\hline
\end{tabular}


Figure 1: Mediating Role of the Need for Justification in Study 3

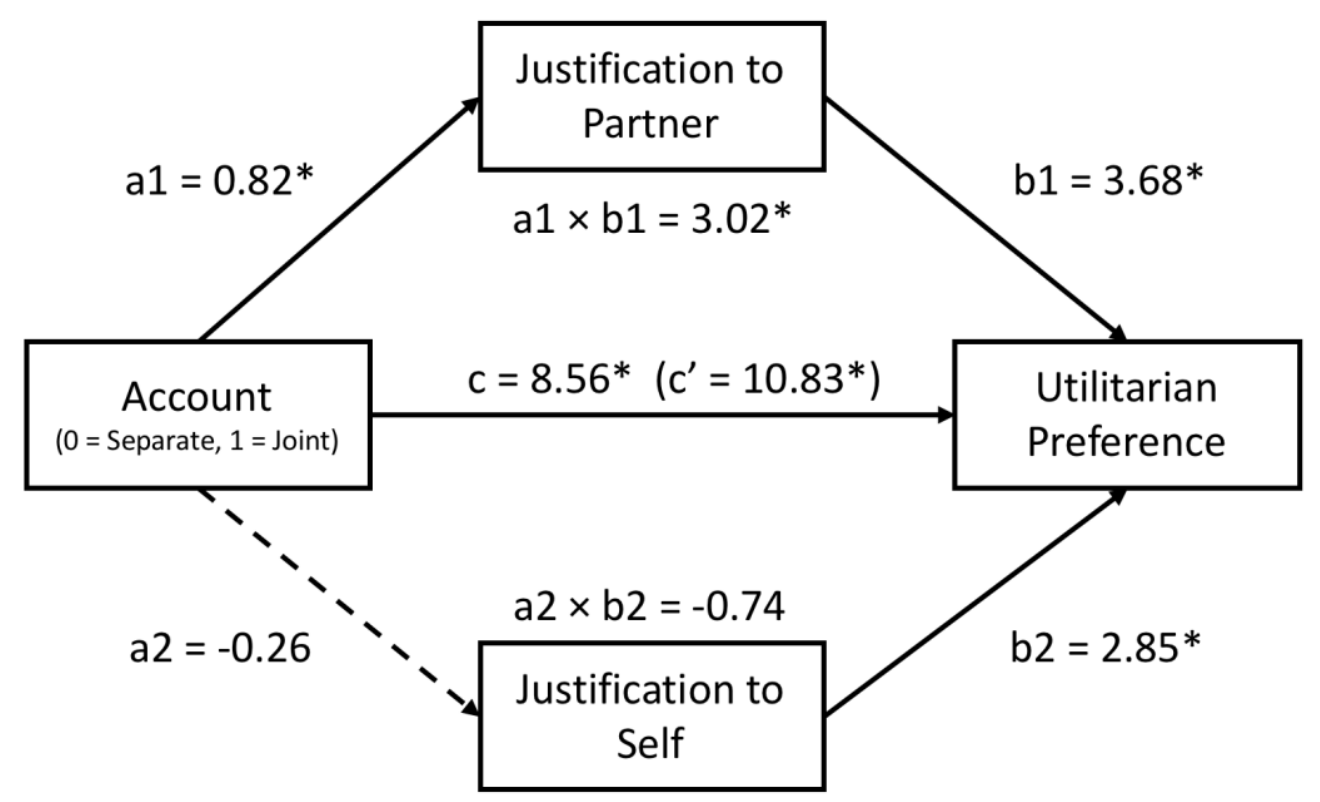

The influence of account type on utilitarian preference strength is mediated by the need for justification to one's partner, but not by the need for justification to oneself. Unstandardized regression coefficients are shown. The first coefficient above the path from account to utilitarian preference represents the direct effect when the mediator is included in the model; the second coefficient above this path in parentheses represents the total effect with no mediator in the model. Coefficients significantly different from 0 are indicated by asterisks $\left({ }^{*} p<.05\right)$ and their associated paths are shown by solid lines; dashed lines indicate non-significant paths. 